\title{
EMPREGO DE GEOTECNOLOGIAS PARA ANALISAR A MOBILIDADE DE BLINDADOS TIPO LAGARTA EM ÁREA DE CAMPO MARA-ZULIA- VENEZUELA
}

\author{
Rhael David Lara Partida ${ }^{(a)}$, Romario Trentin ${ }^{(b)}$ Luís Eduardo de Souza Robaina ${ }^{(\mathrm{c})}$, María José \\ Entrena Pineda ${ }^{(\mathrm{c})}$
}

(a) Departamento de Geociências/Universidade Federal de Santa Maria, rhael.lara5@gmail.com

(b) Departamento de Geociências/Universidade Federal de Santa Maria, romario.trentin@gmail.com

(c) Departamento de Geociências/Universidade Federal de Santa Maria, lesrobaina@yahoo.com.br

(d) Departamento de Geociências/ Universidade Federal de Santa Maria, mariajoseentrena@ gmail.com

\section{Eixo: GEOTECNOLOGIAS E MODELAGEM ESPACIAL EM GEOGRAFIA FISICA}

\begin{abstract}
Resumo
$\mathrm{O}$ rápido desenvolvimento das tecnologias de captura e representação de dados espaciais, coloca à disposição da comunidade científica atual, grande quantidade e variedade de informação georreferenciada. Os quais, dentro de sua análise tradicional com fins de segurança e defesa Nacional, aumentam os tempos necessários para sua consideração nos processos de tomada de decisão. Em tal sentido, surge a necessidade de estimular a familiarização e emprego dos avanços em matéria de geoprocessamento para otimizar a representação em ambiente computacional das características físiconaturais da área de operação, agilizando sua vinculação com outras informações próprias da análise geográfica militar. $\mathrm{O}$ presente trabalho propõe o emprego combinado de geotecnologias $\mathrm{e}$ geoprocesamientos no processo de planejamento de mobilidade blindada sobre lagarta no sector de Campo Mara da bacia do Lago de Maracaibo-Venezuela.
\end{abstract}

Palavras chave: geomorfometria; atributos topográficos; unidades de relevo; bacia hidrográfica; mobilidade.

\section{Introdução}

As geociências em seu uso com fins militares (geografia militar) tem como objetivo produzir conhecimentos sobre o espaço operacional, dando aos comandantes a possibilidade de usá-lo para seu próprio benefício durante o processo de tomada de decisão realizado tanto para o planejamento e para a execução de operações militares, formando um complexo processo de tomada de decisões dinâmico e multidimensional, onde o conhecimento geográfico é a base subjacente às análises realizadas para a seleção de tecnologia e táticas mais adequado para cada situação operacional.

O dinamismo que historicamente tem caracterizado o teatro da guerra, tem impulsionado dentro dos principais exércitos do mundo, a necessidade de geração de informação espacial a ser relacionados a outros fatores na análise geográfica militar. A falta de informação e tecnologias que caracterizou a era pós-guerra incentivou a pesquisa tecnologias para desenvolver dados espaciais e ferramentas 
computacionais para sua manipulação e análise. Gerando uma competição tecnológica que hoje reduziu o tempo necessário para analisar a grande quantidade de informação espacial disponível expandindo as possibilidades consideradas pelos comandantes nos processos de tomada de decisão em ambientes operacionais (HOEPERS e SANTOS, 2001).

Geotecnologias aplicadas em processos de aquisição de informação espacial (imagens de satélite, imagens de radar, etc.), acompanhados por avanços em geoprocessamento que através do uso técnicas computacionais e matemática, permitem o armazenamento processamento e apresentação desta informação, de modo que a sua utilização combinada constitui uma ferramenta de análise espacial que tem sido utilizado em uma grande variedade de aplicações, entre as quais podemos citar: Agronomia, Arquitetura, Cartografia, Engenharia Ambiental, Engenharia Civil, Ambiente, Geografia, Geologia etc. (MOREIRA, 2001).

Entre os avanços em geotecnologias utilizados neste trabalho incluem o uso de modelo digital de elevação ALOS PALSAR resolução espacial de 12,5 m, desenvolvido e distribuído gratuitamente pela agência Japonês de Exploração Aeroespacial (JAXA) e a área de geoprocessamento destaca na compreensão das relações na área geográfica suportada pela geomorfometria que envolve a aplicação de métodos matemáticos e estatísticos para atribuir dimensões para as formas de relevo da terra; facilitando seu estudo em relação à compreensão dos fenómenos que as geram, e sua relação com a atividade humana (PIKE, 2009).

O perfil de curvatura representa a forma da vertente no sentido descendente e indica a proporção de mudança do potencial do gradiente, influenciando no fluxo da água e na velocidade de processos de transporte de sedimentos. O plano de curvatura representa a medida da convergência e divergência topográfica e por isso influencia a concentração de água na paisagem (SIRTOLI et al., 2008).

Hugget (1975) traz a combinação de formas de vertentes associando a curvatura vista em perfil e em plano; propõe nove padrões ideais para indicações das direções dos fluxos da água sobre as vertentes, cujas diferenças nos solos e na paisagem são resultantes, em parte, do movimento da água e sua distribuição nas vertentes.

A análise é realizada utilizando-se como uma unidade de base, a bacia hidrográfica do MaracaiboVenezuela entendida como uma porção da área de terra drenada por um sistema de rio único. Constituindo segundo Trentin (2005) uma porção de peças interligadas que funcionam como um todo completo. Assim, para entender a dinâmica superficial na área da carta topografica Campo Mara (Area do estudo - Figura 01), é necessário compreender as relações entre os parâmetros que interagem no processo global. Neste sentido os seus tamanhos e formas são geralmente determinado pelas condições estabelecidas entre as 


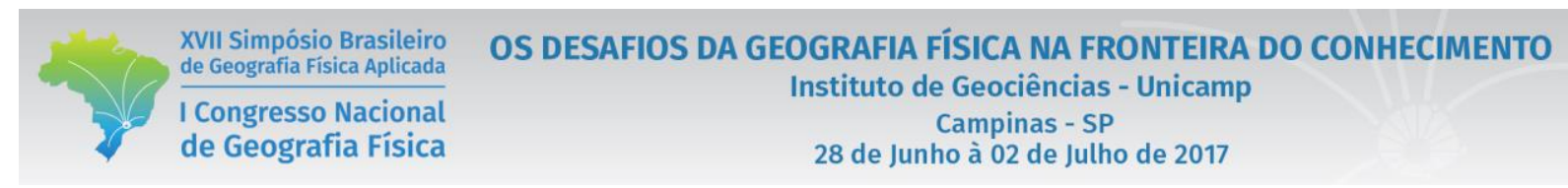

relações geológicas do terreno, padrão e densidade de fluxo de água para o curso de água, relevo, clima, tipo de solo, vegetação e cada vez mais em maior proporção pelas alterações feitas pelo homem. Por esta razão, eles são descritos por Paula Guadagnin (2015), como células naturais, permitindo o reconhecimento e estudo das relações entre os vários elementos da paisagem e os processos que actuem na modelagem. Constituindo uma unidade natural, propício para estudos de conservação ambiental e ordenamento do território (BRADFORD, PETERS, 1987; TRENTIN, 2005; GUADAGNIN, 2014, 2015).

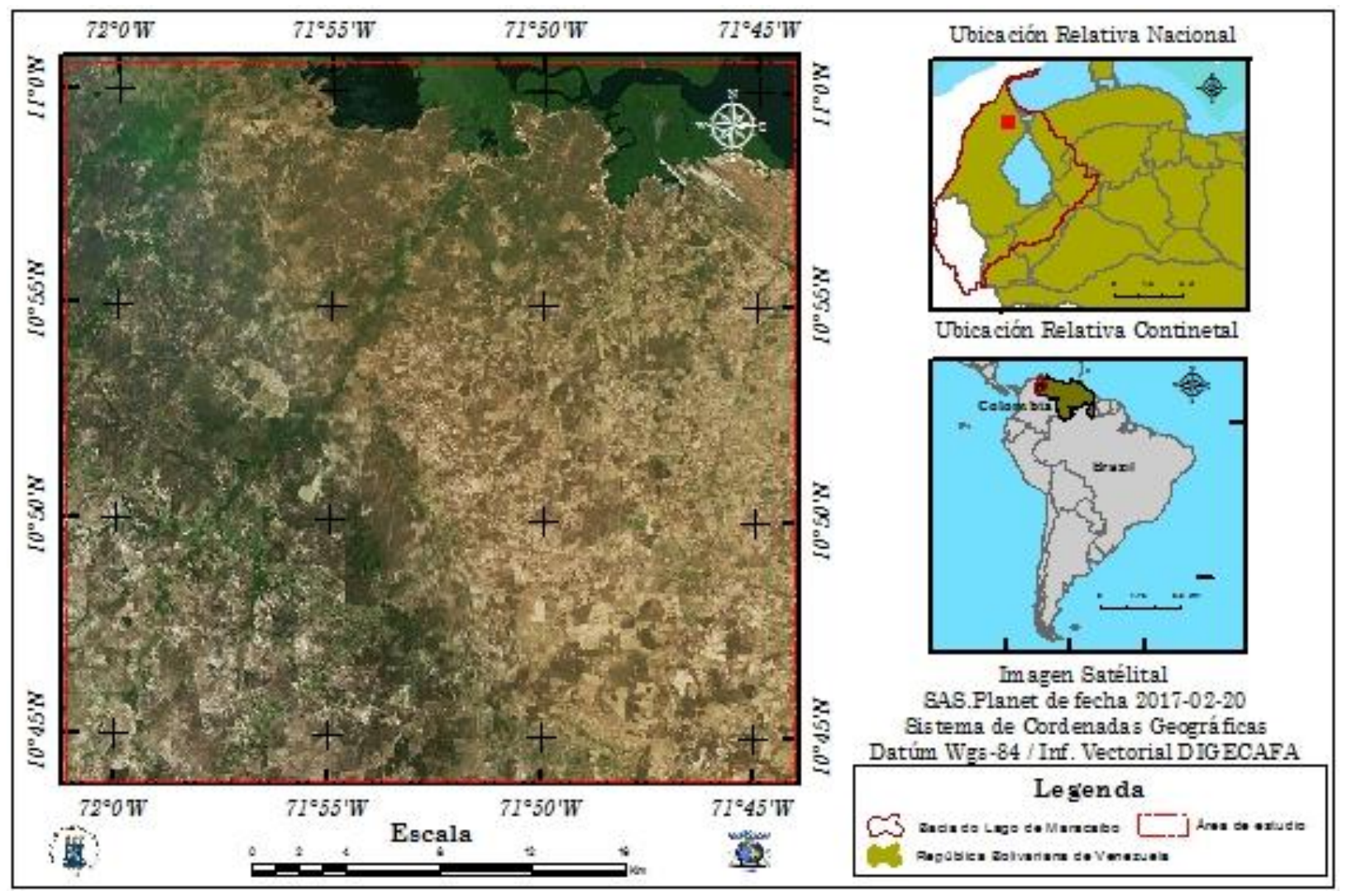

Figura 1- Mapa de localização da área de estudo.

A trafegabilidade blindada será entendida como a capacidade que tem certo tipo de solo, para permitir o trânsito do determinado veículo, por um mesmo local, um certo número de vezes, cuja variação espacial é estudada por a terramecanica a partir da compreensão das leis que regem as relações entre o terreno e o veículo, proporcionando as bases cientificas para sua avaliação, ensaio e analise de comportamento. Com base no entendimento da interfase estabelecida na zona de contato entre a superfície do solo e os elementos de apoio do veículo tipo lagartas (esteiras). Zona na qual se transmitem as forcas produzidas por um sistema de mobilização sobre o terreno. Em tal sentido, para predizer o comportamento do veículo e necessário, portanto, conhecer suas solicitações e a consequente resposta do terreno. Estes 
conhecimentos espaciais influenciam as decisões que se tomam no curso das operações militares, por tanto, se precisa estudar com profundidade e precisão as possibilidades de decisão, de forma que, o comandante e seu estado maior possa prever o grau de manobrabilidade das unidades militares durante $\mathrm{o}$ desenvolvimento da Guerra (BRASIL, 2011; SOARES, 2006; KNOB, 2010).

Partindo da premissa de que, quanto maior e melhor (qualidade) for a informação disponível e quanto mais eficiente sua integração com o processo decisório, mais eficaz o comandante planejará e conduzirá a missão, com maiores possibilidades de obter êxito com o mínimo de perdas (RODRIGUES, 2001).

O trabalho visa utilizar os benefícios das geotecnologia e do geoprocessamento para propor a atualização da camada de mobilidade militar dentro de um banco de dados em ambiente SIG e promover a familiarização de profissionais na área da geografia militar com a sua aplicação como ferramentas de suporte para a contemporânea análise militar.

\section{Material e Método:}

Para a realização da análise espacial de mobilidade blindada na área da carta topográfica 1:50.000 Campo Mara, localizada na parte nordeste da planície aluvial da Bacia hidrográfica do Lago de Maracaibo Figura 01. Será considerada a regionalização estabelecida pela Comissão do Plano Nacional de Aproveitamento dos Recursos Hidráulicos (COPLANARH 1974), os resultados obtidos nos perfis de solos tomados na área de estudo, definidas por Jiménez L. et ao (1995), as técnicas de mapeamento geomorfométrico automatizado apresentado por Silveira \& Silveira (2014) a partir dos preceitos de Iwahashi e Pike (2007) e os parâmetros de resistência ao movimento blindado sobre lagartas do Exército Brasileiro (BRASIL 2011), hierarquizados com as ferramentas de avaliação multicritério disponíveis dentro do ambiente SIG de ARGIS 10.1.

Para representar em ambiente computacional os diferentes graus de resistência ante o movimento blindado exercido pelo terreno parte-se do entendimento das diferentes respostas dos solos ante a mobilidade sobre lagarta, que devido às particularidades da área de estudo é conceituado como o fator com maior influência ante esta tecnologia de mobilidade. O relevo do setor é praticamente plano mas seus solos que se caracterizam pelo predomínio de frações arenosas em sua camada superficial com um marcado incremento em seu conteúdo de argila proporcional à profundidade. Apresentam setores com problemas de erosão ativa muito graves e setores com erosão moderada que possibilitam sua hierarquização por seus diferentes graus de resistência ao movimento blindado sobre lagarta.

Em tal sentido, o entendimento das relações sistêmicas que explicam estas diferenças de ambientes formadores de solos, serão sustentados pela análise dos resultados nos estudos de perfis de solo realizado 
por Jiménez (1995), onde se constatou a existência de duas classes de solos argilosos diferenciados pela cor da matriz do solo e suas capacidades de resistência de carga, os quais foram denominadas argilosos amarelos para diferenciar os que apresentam cores com matizes mais amarelos que 7.5YR (figura $2 \mathrm{~A}$ ) dos que apresentam matrizes de solo com cores mais vermelhas que 7.5YR (Figura $2 \mathrm{~B}$ ).

Solo com Horizonte Argiloso Amarelo

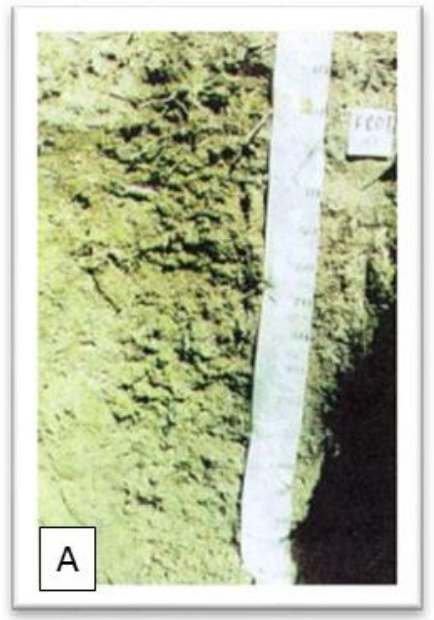

Solo com horizonte argiloso vermelho

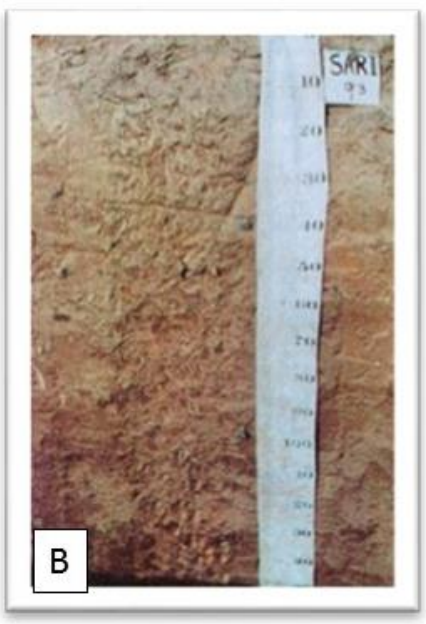

Figura 2 - Tipos de horizontes argílicos da área de Campo Mara.

Mediante o estudo de perfis de solo realizado por Jiménez (1995) tabela I constatou-se que a densidade aparente a nível de horizontes argiloso para a classe amarela variou entre 1,5 e 1,98 g/cc enquanto para os vermelhos variou entre 1,56 e 1,72 g/cc. Os valores altos de densidade nos argilosos amarelos atribuíramse a processos de endurecimento por ferro, materiais com muito baixos conteúdos de humidade e conteúdos maiores de areia muito fina e limo. A infiltração básica dos solos com argilosos amarelos variou entre 0,79 e $4,5 \mathrm{~cm} / \mathrm{h}$ e para solos com argílosos vermelhos variou entre 0,58 e 7,9 cm/h. Os valores baixos de infiltração básica relacionaram-se com problemas de compactação na camada superficial, enquanto os valores altos associaram-se com argilosos profundos e camadas superficiais mais arenosas (JIMÉNEZ, 1995).

Tabela I- Quadro Comparativo

\begin{tabular}{l|l|l}
\hline & Densidade a Nível de Horizontes Argilosos & Infiltração Básica \\
\hline Argilosos Amarelos & 1,5 a $1,98 \mathrm{~g} / \mathrm{cc}$ & 0,79 a $4,5 \mathrm{~cm} / \mathrm{h}$ \\
\hline Argilosos Vermelhos & 1,56 a $1,72 \mathrm{~g} / \mathrm{cc}$. & 0,58 a $7,9 \mathrm{~cm} / \mathrm{h}$ \\
\hline
\end{tabular}

Mediante a análise das características físicas de ambos perfis argilosos se realizou a hierarquização por seus graus de influência ante a mobilidade blindada, onde em linhas gerais os solos argilosos amarelos 
(com maiores quantidades de areia muito fina e limo) localizados primordialmente nas áreas secas oferecem menos resistência ao movimento blindado que os solos com argilosos vermelhos (com problemas de compactação em sua camada superficial) localizados primordialmente em ambientes úmidos. Bem como também se conseguiu associar a intensificação dos problemas erosivos às áreas com maior concentração de umidade (planos convergentes). Em tal sentido, a proposta de mapeamento geomorfométricos automatizado apresentada por Silveira \& Silveira (2013) constitui uma ferramenta de especialização para ambientes que favorecem a formação dos tipos de solos presentes na área de estudo, bem como também para a identificação dos setores onde os processos erosivos são dinamizados pela convergência dos fluxos de água estimulando a formação de ravinas, as quais afetam a manobrabilidade blindada de forma considerável.

Tal classificação é realizada através do cruzamento de informações e atributos topográficos gerados por meio de um SIG e hierarquizados através de uma árvore de decisão baseada em valores pré-definidos, com base em conhecimento da área e as características técnicas os blindados analisados. Foram empregados quatro (04) atributos topográficos: altimetria, declividade, perfil de curvatura e plano de curvatura. Como base cartográfica utilizada para a geração dos atributos topográficos, utilizou-se as curvas de nível de equidistância de $10 \mathrm{~m}$ as quais foram extraídas do Modelo Digital do Elevação ALOS PALSAR - 12,5 m as informações altimetrias e hidrográficas presentes nas cartas topográficas da Diretoria de Geografia e Cartografia do exército Venezuelano, em escala 1:50.000, da área de estudo. Através dos mesmos, realizou-se a interpolação destas informações utilizando-se o interpolador topo to raster, disponível como ferramenta no aplicativo ArcMap versão 10.1 (ESRI, 2013), que cria um modelo digital do terreno hidrologicamente consistentes, a partir dos seguintes parâmetros: curvas de nível, pontos cotados, limite da área de estudo e a hidrografia.

Utilizando o histograma de frequência definiu-se a altitude 0 metros. A escolha por este valor como limite corresponde ainda à sua proximidade com uma situação de quebra da capacidade do solo para permitir o transito blindado sobre lagartas, ou seja, a saturação dos solos por sua proximidade ao nível freático restringe este tipo de tecnologia de mobilidade militar. A partir deste modelo digital de terreno, são geradas as demais informações pertinentes à compartimentação geomorfométrica.

As vertentes segundo Veloso (2002), podem ser definidas de forma simplificada como um elemento da superfície terrestre inclinado em relação à horizontal, que apresenta um gradiente e uma orientação no espaço, e dessa forma podem ser classificadas de acordo com a sua curvatura no plano ou em perfil. O plano de curvatura da vertente são também informações derivadas do MDT e corresponde à variação do gradiente de arqueamento na direção ortogonal da vertente (curvatura da superfície perpendicular à 
direção da inclinação) e refere-se ao caráter divergente/convergente do terreno, enquanto, o perfil de curvatura é a taxa de variação do gradiente de arqueamento na direção de sua orientação (a curvatura da superfície no sentido do declive) e está relacionada ao caráter convexo/côncavo do terreno sendo decisiva na aceleração ou desaceleração do fluxo da água durante seu escoamento sobre o mesmo. Ambos foram obtidos a partir do MDT usando a ferramenta curvature (ArcMap versão 10.1).

O perfil das vertentes, em ambiente SIG, é analisado de acordo com seu valor de curvatura (histograma de frequência) e teoricamente, vertentes retilíneas têm valor de curvatura nulo, vertentes côncavas os têm positivos e convexas têm curvatura negativa (VALERIANO, 2003).

Porém, vertentes com valores nulos são muito raras na natureza, assim muito pouco do que se julga retilíneo apresenta valor de curvatura realmente nulo, mas sim valores pertencentes a um intervalo de tolerância na vizinhança desse valor. A classificação do plano das vertentes, em ambiente SIG, é analisada de acordo com o seu histograma de frequência que indica o valor da referida curvatura. Semelhante ao perfil, os valores nulos correspondem à inexistência de curvatura em vertentes planas, já os valores positivos representam curvatura divergente e os valores negativos correspondem à curvatura convergente. Para a compartimentação geomorfométrica do referido trabalho, optou-se pela classificação das curvaturas das vertentes em duas classes: quanto ao perfil em côncavas e convexas e quanto ao plano em convergentes e divergentes, conforme Tabela II.

Tabela II- Classificação das informações básicas para a determinação das unidades geomorfométricas.

\begin{tabular}{l|l|l|l}
\hline Altitude & Declividade & Plano & Perfil \\
\hline $1-<0$ metros & $1-<35 \%$ & $1-$ Convergente & $1-$ Convexo \\
\hline $2->0$ metros & $2->35 \%$ & $2-$ Divergente & 2 - Côncavo \\
\hline
\end{tabular}

Fonte: Os autores.

No cruzamento das informações utilizando-se a árvore de decisão apresentada no fluxograma (Figura 3), donde foram identificadas 5 unidades geomorfométricas que representam a distribuição espacial das respostas do relevo ante a mobilidade blindada sobre lagarta. 

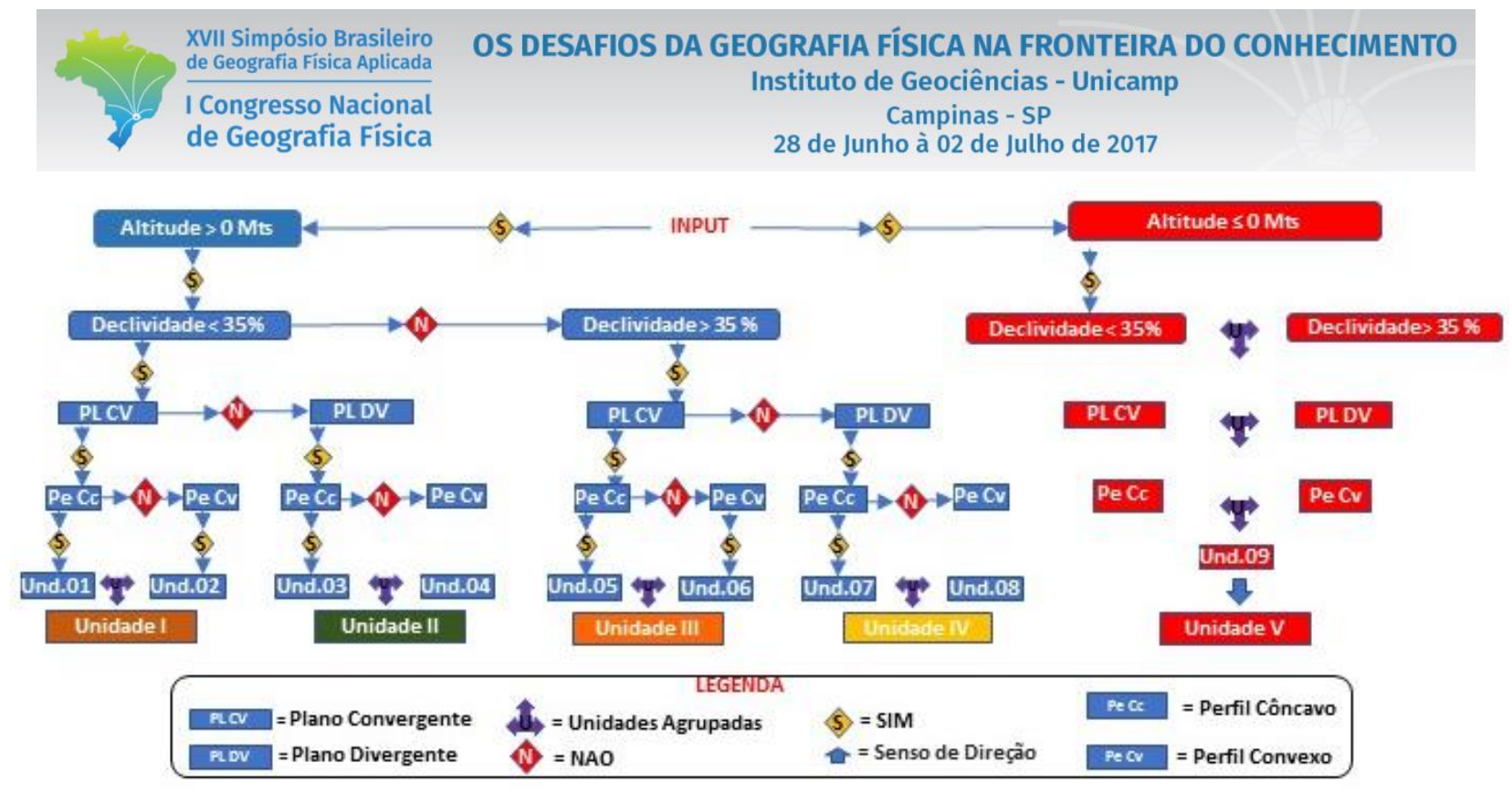

Figura 3 - Fluxograma apresentando a árvore de decisão utilizada para a definição das unidades geomorfométricas.

Para a hierarquização da hidrografia Tabela III, empregou-se a informação extraída da carta topográfica a escala 1: 50.000 Campo Mara e os parâmetros de restrição ao movimento imposto pela hidrografia ante a mobilidade blindada do exército Brasileiro (BRASIL 2011).

Tabela III - RESTRIÇÕES IMPOSTAS PELA HIDROGRAFIA

\begin{tabular}{l|l}
\hline CLASSIFICAÇÃO & HIDROGRAFIA \\
\hline Impeditivo & $\begin{array}{l}\text { Cursos d'água, lagos, pântanos, zonas alagadiças, que não possam ser vadeados ou } \\
\text { atravessados com apoio de Pontes Lançadas por Viaturas Blindadas (PLVB) pela } \\
\text { engenharia militar. Margens verticais de superfície firme, que possam deter os } \\
\text { carros-de-combate, assim como correnteza com velocidade elevada e profundidade } \\
\text { que apresente desvantagens para viaturas blindadas. }\end{array}$ \\
\hline Restritivo & $\begin{array}{l}\text { Cursos d'água, lagos, áreas alagadiças, que possam ser vadeados ou atravessados } \\
\text { com apoio de PLVB em vários locais. A velocidade da correnteza deve ser pequeña } \\
(<1,5 \mathrm{~m} / \mathrm{s}) \text { e a profundidade debe ser inferior a } 1,20 \mathrm{~m} .\end{array}$ \\
\hline Adequado & $\begin{array}{l}\text { Cursos d'água, lagos, que possam ser vadeados em qualquer lugar ou que tenham } \\
\text { largura }<1,5 \mathrm{~m} . \text { A profundidade }<0,6 \mathrm{~m} \text { e a velocidade da correnteza não deve } \\
\text { impedir a travessia. }\end{array}$ \\
\hline
\end{tabular}

Fonte: BRASIL 2011.

Para espacializar os diferentes tipos de vegetação Tabela IV presentes na área de estudo empregou-se o Normalized Difference Vegetation Index (NDVI) extraído dá imagem landsat 8 Sensor Operational Land Imager (OLI) de data 17 FEB 2017 hierarquizadas segundos os parâmetros de restrição ao movimento blindado imposto pela vegetação do exército brasileiro (BRASIL 2011). 
Tabela IV - Restrições impostas pela vegetação.

\begin{tabular}{l|l}
\hline CLASSIFICAÇÃO & VEGETAÇÃO \\
\hline Impeditivo & $\begin{array}{l}\text { Grupo de árvores que impeçam o emprego de forças blindadas ou dificultem o } \\
\text { movimento de tropas a pé. }\end{array}$ \\
\hline Restritivo & $\begin{array}{l}\text { Árvores espaçadas com diâmetros reduzidos que restrinjam o movimento de forças } \\
\text { blindadas. }\end{array}$ \\
\hline Adequado & $\begin{array}{l}\text { Árvores espaçadas com diâmetros reduzidos, não interferindo no emprego de } \\
\text { viaturas ou tropas a pé. }\end{array}$ \\
\hline
\end{tabular}

Fonte: BRASIL 2011.

\section{Resultados obtidos}

$\mathrm{Na}$ parte norte dá área de estudo encontram-se localizados solos deprimidos da planície aluvial da bacia Hidrográfica do lago do Maracaibo com cotas altimétricas negativas de até - 28,5 metros as quais são ocupadas pelas águas do lago (Cienaga de Sinamaica, Cienaga a Tigra) e a maior cota é de 150 metros localizada em sua parte sul no (Cerro El Cochino), resultando em uma amplitude altimétrica de 178,5 m.

Baseando-se nos valores do NDVI foram definidos quatro (04) setores de vegetação presentes na área de estudo tabela V.

Tabela V- Restrição ao Movimento Blindado sobre lagartas por Vegetação.

\begin{tabular}{l|c|c}
\hline \multicolumn{1}{c|}{ Setores } & Área (ha) & Porcentagem (\%) \\
\hline ÁGUA & $1.968,66$ & 2,59 \\
\hline SOLO DESNUDO & $31.341,33$ & 41,38 \\
\hline ESPINARES RALOS & $35.412,30$ & 46,76 \\
\hline $\begin{array}{l}\text { BOSQUE DE GALERIA E } \\
\text { MANGUEZAL }\end{array}$ & $7.009,20$ & 9,25 \\
\hline
\end{tabular}

Fonte: Os autores.

As quais foram classificadas de acordo à parametrização proposta pelo exército Brasilero (BRASIL 2011) Figura 4.

Baseando-se nos parâmetros descritos foram classificados os tipos de vertentes presentes na área a partir de suas características geomorfometricas Figura 4, para definir 05 (cinco) unidades com direfentes graus de influência ante a mobilidade blindada sobre lagarta (Ambientes formadores de solo e Declividade) os quais foram classificados de acordo à parametrização proposta pelo exército Brasileiro (BRASIL 2011). 

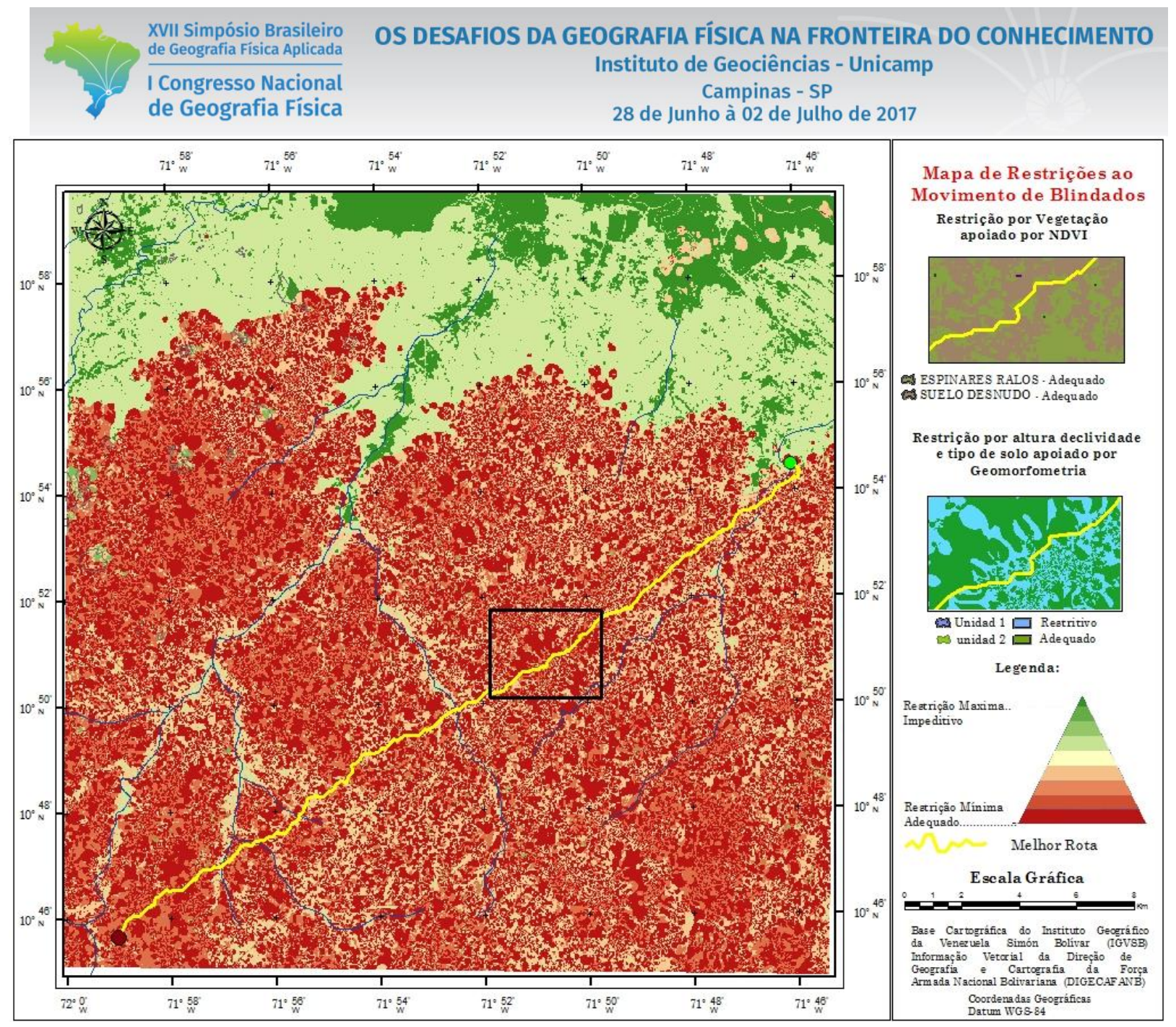

Figura 4 - Mapa de definição dos níveis de influência ante a mobilidade blindada sobre lagartas por: Vegetação, Ambiente geomorfometrico formador do solo, Declividade e Hidrografia (BRASIL 2011).

A unidade I ocorre em 25.410,63 ha, representando 33,5 \% do total da área do estudo (Tabela VI), sendo mais expressiva na área correspondente a planície aluvial. Corresponde a terrenos sujeitos a processos de acumulação de água e materiais (plano convergente) com alturas $>0$ metros e declividades $<35 \%$ conformando ou ambiente ideal que por médio da sedimentação formam os solos com perfil argilosos vermelho classificado de acordo a seus caracteristicas físicas e os parâmetros de restrição ao movimento sobre lagartas como Restritivo.

Tabela VI - Áreas e respectivas porcentagens das unidades geomorfométricas.

\begin{tabular}{l|c|c}
\multicolumn{1}{c|}{ Unidade } & Área (ha) & Porcentagem (\%) \\
\hline Unidade I & $25.410,62$ & 33,53 \\
\hline Unidade II & $31.030,7$ & 40,95 \\
\hline Unidade III & 0,10 & 0,00014 \\
\hline
\end{tabular}




\begin{tabular}{l|c|c}
\hline Unidade IV & 3,57 & 0,0047 \\
\hline Unidade V & $19.317,89$ & 25,50 \\
\hline
\end{tabular}

Fonte: Os autores.

A Unidade II ocorre em 31.030,77 ha, representando 41 \% do total da área, sendo mais expressiva na área correspondente a ampla planície aluvial, onde os processos de dissipação do fluxo de água e materiais (Plano Divergente) favorecendo os processos de ampliação da planície e formação os solos com perfil argiloso amarelo classificado de acordo a suas características físicas e os parâmetros de restrição ao movimento sobre lagartas como adequados.

A Unidade III e Unidade IV ocorrem em 0,1 e 3,6 ha respectivamente, representando $0,005 \%$ do total da área, onde as declividades $>35 \%$ são localizadas em muito pouca expressão em uma pequena área chamada "Cerro El Cochino" onde a mobilidade blindada sobre lagarta é conceituada como Restritivo.

A Unidade V ocorre em 19.317,89 ha representando $25,50 \%$ do total dá área, sendo expressiva no setor pantanoso ao norte da área do estudo, onde a saturação dos solos localizados próximos ao nível freático (Alturas $\leq 0)$ diminuem sua resistência ao suporte de carga restringindo a mobilidade blindada sobre lagarta (Inpeditiva).

\section{Considerações finais:}

As análises sistêmicas apoiadas com técnicas de geotecnologias e geoprocessamentos, constituem ferramentas de análise espacial adequadas para fortalecer os processos de tomada de decisões, focados em empregar as capacidades das unidades militares de acordo com as características específicas de cada espaço geográfico.

É possível estabelecer relações sistêmicas entre compartimentalização geomorfometrica e outras características do meio físico (substrato geológico, ou clima e hidrografia) e diferenciar setores com diferentes ambientes de formação do solo, vegetação etc. Além disso, a partir deste entendimento, é possível subsidiar ou planejamento e ordenamento do território para diversos fins, como por exemplo na sua utilização para fins de defesa territorial com a definição de mobilidade militar.

A eficiência da aplicação de ferramentas computacionais para subsidiar os processos de tomada de decisão em ambientes operacionais, depende da correta atribuição de pesos ou graus de influência à cada um dos fatores conceituados, os quais varian com os tipos de tecnologias e as características geograficas da cada área de operação, incluindo suas alterações temporárias como por exemplo as pluviométricas que variam consideravelmente os graus de resistência ao movimento exercidas pelos solos. A complexidade das análises geográficas de indole militar reafirma a importância do especialista em geografia cuja formação, 
tanto acadêmica como profissional (experiência in sito) lhe permitirá relacionar eficientemente as características tanto do espaço físico natural (Clima, geologia, relevo, hidrografia, vegetação etc.) como do espaço humano (adestramento, estado moral, motivacional etc.) com as atividades operacionais.

\section{Bibliografia:}

BRADFORD, MARIE E.; PETERS, ROBERT H. The relationship between chemically analyzed phosphorus fractions and bioavailable phosphorus. the American Society of Limnology and Oceanography, Montreal, n. 32(5), Limnol Oceanogr, p.1124-1137, 1987.

BRASIL. Ministério da Defesa, Exército Brasileiro. Diretriz de Trafegabilidade para Viaturas sobre Rodas e sobre Lagartas. Brasília, DF, 2011.

COPLANARH. 1974. Inventario nacional de tierras, región Lago de Maracaibo. Publicación N\# 34. Caracas.

GUADAGNIN, P.M. Caracterização e mapeamento da vegetação florestal e sua relação com os componentes do relevo na bacia hidrográfica do arroio Caverá - Oeste do RS/ Brasil. 2015. 101 p. Dissertação (Mestrado em Geografia) - Universidade Federal de Santa Maria, Santa Maria, 2015.

GUADAGNIN, PAULA MIRELA ALMEIDA; TRENTIN, ROMARIO. Compartimentação Geomorfométrica da Bacia Hidrográfica do Arroio Caverá-RS. Geo UERJ, v. 1, n. 25, p. 183-199, 2014.

HOEPERS, G.; SANTOS, N.A.L. O Geoprocessamento Aplicado ao Método de Estudo Militar do Terreno. Monografia (Especialização em Geoprocessamento) - Laboratório de Sensoriamento Remoto, Instituto de Geociências, Universidade de Brasília - UnB, Brasília: 2001.

HUGGET, R. J. Soil Landscape Systems: A model of soil genesis. Geoderma, v.13, p.01-22, 1975.

JIMÉNEZ F. L et al. Caracterización Física, Química, Mineralógica y Micromorfológica de Horizontes Argílicos en la Altiplanicie de Maracaibo. Revista de la Facultad de Agronomía de la Universidad del Zulia (LUZ), Maracaibo - Venezuela, Vol. 12, N. 01, 1995. Rev.Fac. Agron. LUZ, p. 4757.

KNOB, M. J. Estudo de Trafegabilidade Aplicado a Veículos de Roda em Transporte e Tração. 2010. 153 f. Tese (Doutorado em Engenharia Agrícola)-Universidade Federal de Santa Maria, Santa Maria, RS, 2010.

MOREIRA, M. A. Fundamentos do Sensoriamento Remoto e Metodologias de Aplicação. 1. ed. São José dos Campos: Ed. Com Deus, 2001. 250p.

PIKE, Richard J.; EVANS, I.S.; HENGL, T. Geomorphometry: A Brief Guide. In: GEOMORPHOMETRY: Concepts, Software, Applications, 1. ed. Amsterdam: Elsevier, 2009.707 p. 
RODRIGUES, C. A teoria geossistêmica e sua contribuição aos estudos geográficos e ambientáis, São Paulo (SP).

Rev. Do Departamento de Geografia, USP, n.14, p. 69-77, 2001.

SILVEIRA, Ricardo; SILVEIRA, Claudinei. Clasificación Morfológica del Relieve de Uruguayo Basada en Modelos Digitales de Elevación y Técnicas Geomorfométricas. Geografía y Sistemas de Información Geográfica (GEOSIG), Luján, Argentina, año 6, n. 6, 2014. Departamento de Geografia, p. 19-36.

SIRTOLI, A. E.; SILVEIRA, C. T.; MONTOVANI, L. E.; SIRTOLI, A. R. A.; OKA-FIORI, C. Atributos do relevo derivados de modelo digital de elevação e suas relações com solos. Scientia agraria, v.9, n.3, p.317-329, 2008.

SOARES, I.C. O uso da análise espacial no Processo de Integração Terreno, Condições Meteorológicas e Inimigo (PITCI) do Exército Brasileiro. 2006. 94 p. Dissertacao (Maestrado em educacion)- Universidade de Brasília, Brasília, DF, 2006.

TRENTIN, R.; ROBAINA, L. E. S. Metodologia para Mapeamento Geoambiental no Oeste do Rio Grande do Sul. In: XI SIMPÓSIO BRASILEIRO DE GEOGRAFIA FÍSICA APLICADA, 2005, Anais. São Paulo, USP, 2005. 